\title{
ATRASOS NA EXECUCÃO DAS OBRAS PÚBLICAS: ESTUDO EM UMA INSTITUIÇẢOO FEDERAL DE ENSINO SUPERIOR
}

\section{DELAYS IN THE IMPLEMENTATION OF PUBLIC WORKS: CASE STUDY IN A FEDERAL INSTITUTION OF HIGHER EDUCATION}

\author{
Iliane Colpo*E-mail: ilicolpo@gmail.com \\ Andreas Dittmar Weise* E-mail: andreas.weise@ufsm.br \\ Flaviani Souto Bolzan Medeiros* E-mail: flaviani.13@gmail.com \\ Mauri Leodir Lobler* E-mail: mllobler@gmail.com \\ *Universidade Federal de Santa Maria (UFSM), Santa Maria, RS
}

\begin{abstract}
Resumo: A teoria da "nova" administração pública traz em seu âmago a eficiência dos processos, contudo, a aplicação na prática desse princípio tem sido questionada pela sociedade, especialmente frente ao montante das cifras gastas para a conclusão de obras públicas. A falta de planejamento, alterações em projetos, desvios de recursos e o retrabalho tem sido citado como algumas variáveis que contribuem para essa situação. Nesse sentido, este artigo tem por objetivo analisar os contratos de obras de uma Universidade Federal, do período de 2010 a 2014, a fim de identificar o tempo médio dos atrasos nas obras e a justificativa escrita dos aditivos de prazo para a execução dos serviços pactuados entre as construtoras e a administração pública. Em termos metodológicos, a pesquisa é classificada quanto aos meios como documental e quanto aos fins como descritivo. Dentre os resultados, o estudo revela que $80,35 \%$ das obras apresentam termo aditivo de tempo, desconsiderando os contratos rescindidos o percentual é de $75,55 \%$, nestes casos, o atraso é de $48,94 \%$ em relação ao tempo médio planejado. Nas justificativas dos atrasos a alteração dos projetos aparece com $33,34 \%$ o que indica uma falta de planejamento na fase interna do processo de licitação.
\end{abstract}

Palavras-chave: Obras Públicas. Execução dos Serviços. Aditivos de Tempo.

Abstract: The theory of the "new" public administration brings in its core the efficiency of the processes, however, the practical application of this principle has been questioned by society, especially against the amount of the figures spent for the conclusion of public works. The lack of planning, changes in projects, diversions of resources and rework has been cited as some variables that contribute to this situation. In this sense, this work aims to analyze the works contracts of a Federal University, from the period of 2010 to 2014, in order to identify the average time delays in the works and the written justification of the additives of term for the execution of the agreed services Between the builders and the public administration. In methodological terms, the research is classified as means as documentary and as for the purposes as descriptive. Among the results, the study reveals that $80.35 \%$ of the works have an additive term, disregarding the rescinded contracts, the percentage is $75.55 \%$, in these cases, the delay is $48.94 \%$ in relation to the average time planned. In the justifications for delays, the change in projects appears with $33.34 \%$, which indicates a lack of planning in the internal phase of the bidding process.

Keywords: Public Works. Execution of Services. Time Additives. 


\section{INTRODUÇÃO}

O interesse da sociedade acerca do comportamento da administração pública e da destinação dos recursos públicos é crescente e positivo no sentido de restringir ações inadequadas, e também, é um dos fatores da necessidade de transparência e eficiência no processo administrativo. A eficiência, princípio básico da administração pública, é imposta aos agentes públicos na realização de suas atribuições e para que ela possa ser atingida as ações devem ser mensuradas e avaliadas sistematicamente.

Neste aspecto, os contratos de obras públicas pactuados entre os órgãos públicos e a iniciativa privada é um tema frequente de inquietação da sociedade. Para Meirelles (1998), a obra pública é enquadrada como um fato administrativo e, portanto, sujeito aos regulamentos da administração pública. Para a contratação da execução de forma indireta das obras públicas um conjunto de regras e ritos deverá ser seguido. No processo licitatório, o edital apresenta o tempo planejado para a execução total do contrato e as construtoras concorrem no procedimento licitatório em função do preço apresentado para execução da obra no tempo planejado pela administração pública.

Contudo, Odeh e Battaineh (2002) alertam que a maioria dos projetos públicos em países em desenvolvimento excede as estimativas iniciais tanto de tempo como de custo. E o Brasil não é uma exceção (SANTOS; STARLING; ANDERY, 2015). Oliveira, Guelbert e Guelbert (2016) reforçam que os atrasos consistem na principal causa da baixa qualidade e do aumento dos custos nas construções, inclusive, sendo este um problema crônico que afeta a construção civil seja em nível de Brasil seja mundialmente.

Sob esse enfoque, Coutinho (2010) salienta que o tempo é uma das variáveis mais importantes do ramo da construção civil, podendo ser um agente negativo, afetando a produção e a qualidade. Além disso, Antunes (2012) lembra que, de modo geral, o impacto do atraso na construção incide de forma direta no resultado da obra e, na maioria das vezes, um tempo menor representa diretamente um custo menor.

Então, é perceptível que o planejamento e a execução de obras públicas envolvem decisões e ações complexas, sendo assim, Bittencourt e Ferreira (2014) 
ponderam que se faz necessário levar em conta, entre outros aspectos, a otimização de recursos onde para se alcançar os resultados esperados é preciso o envolvimento de diversos atores neste processo, tais como: diferentes esferas governamentais, o setor privado e outros grupos de interesse além, é claro, da legislação em vigor. Dessa forma, a ausência ou a elaboração de forma inadequada do planejamento de uma obra gera prejuízos para todos os envolvidos (STRAPASSON; SANTOS; SANTOS, 2010).

Rasmussen (2013) explica que quando o contrato assinado entre a empresa e o órgão público não pode ser cumprido em virtude de não conseguir atender as demandas da obra, em função do custo ou do orçamento, para que não seja necessário outro processo licitatório, aumentando ainda mais o custo final da obra, uma das soluções é o aditamento de custo ou de prazo seguindo os preceitos da Lei 8.666/93.

Todavia, mesmo os aditamentos de tempo causam prejuízos não apenas a construtora, mas às instituições, uma vez que gera retrabalho aos setores envolvidos e a necessidade de mais recursos humanos no desenvolvimento das tarefas, de frustração da sociedade pelo não cumprimento do prometido e de não poder utilizar o ambiente cujo recurso financeiro já foi comprometido. Portanto, o atraso e o aumento de custos não são benéficos nem para a sociedade como um todo, tampouco, aos que esperam usufruir diretamente com a entrega da obra, e no caso das instituições de ensino isso não é diferente.

Isso porque acarreta na interrupção de projetos já em andamento, bem como impede a elaboração de outros novos, o que significa conhecimentos gerados limitados diante de tal entrave e, consequentemente, ficam a espera da sua divulgação à comunidade em geral. Sem contar nos recursos que poderiam ser alocados em outras edificações que precisassem de melhorias e/ou ampliações, entretanto, em função da falta de planejamento e devido acompanhamento da execução, acabam sendo injetados na tentativa de conclusão da obra pendente.

Diante do exposto, o objetivo deste trabalho é analisar os contratos de obras de uma Universidade Federal, do período de 2010 a 2014, a fim de identificar a média de atraso dos processos e a justificativa escrita dos aditivos de prazo para a execução dos serviços pactuados entre as construtoras e a administração pública. 
A justificativa e a relevância do estudo se apresentam em dois aspectos: 0 primeiro social, no intuito de apresentar a sociedade um estudo do tempo de execução de obras públicas numa instituição federal de ensino superior; e o segundo do aspecto de gestão, com o propósito de auxiliar o gestor público na melhoria dos processos internos, na busca da eficiência institucional.

Este trabalho está estruturado em três seções, a saber: com início nesta introdução, já a seção dois traz o desenvolvimento da pesquisa onde se encontra a fundamentação teórica, os procedimentos metodológicos adotados, e ainda, contempla a apresentação e análise dos resultados. Por último, a seção três encerra o artigo com as considerações finais.

\section{DESENVOLVIMENTO}

\subsection{Fundamentação teórica}

2.1.1 A teoria da administração pública e a contratação indireta de obras

A administração pública dita como o conjunto de órgãos, serviços e agentes do Estado que tem como objetivo assegurar a satisfação das necessidades da sociedade, articulando os materiais disponíveis (ferramentas, recursos) em prol do interesse coletivo para atingir o maior número de pessoas possíveis. Este trabalho encontra amparo na teoria da nova administração pública, também chamada de gerencial, com foco legal e base no resultado. A eficiência passa a ser o ponto a ser estimulado.

O próprio art. 37 da Constituição Federal (Brasil, 1988) traz os princípios da administração pública, são eles: legalidade; impessoalidade; moralidade; publicidade; e eficiência. Dentre estes, o princípio da eficiência tem sido o mais desafiador para os gestores públicos. Pode-se citar como significado de eficiência o conceito preconizado por Peter Drucker: realizar operações com menos recursos, menos tempo e menor orçamento.

Neste aspecto fica explicita a necessidade de mensuração das ações para que seja possível avaliar e verificar se houve uma gestão eficiente. Na contratação de obras públicas, além dos princípios já citados, também é necessário que o gestor 
siga o rito legal, observando um conjunto de procedimentos, normas e orientações da legislação vigente.

A Lei 12.349/10 (Brasil, 2010) justifica a finalidade das normas nas compras públicas, revelando que ela "destina-se a garantir a observância do princípio constitucional da isonomia, a seleção da proposta mais vantajosa para a administração e a promoção do desenvolvimento nacional sustentável". Porém, Barreto e Souto (2008, p. 29) advertem que "o risco que se corre neste modelo é o que os meios passem a ser considerados mais importantes do que os fins. $O$ excesso de formalismo pode, muitas vezes, comprometer a eficiência do sistema".

Vários autores concordam que a proposta mais vantajosa é aquela que atende os interesses da administração pública e da motivação do procedimento licitatório (CARVALHO FILHO, 2013; DI PIETRO, 2013; JUSTEN FILHO, 2014; MELLO, 2013). As fases do processo licitatório são definidas de acordo com a modalidade determinada pelo gestor público e esta escolha leva em consideração o valor global da aquisição. No art. 22 da Lei 8.666/93 (Brasil, 1993) são citadas as seguintes modalidades de licitação: Concorrência; Tomada de preços; Convite; Concurso; e Leilão. As modalidades estabelecem as formas que o procedimento de licitação será apresentado. Além das modalidades descritas, a Lei 10.520/02 (Brasil, 2002) institui uma sexta modalidade de licitação, denominada pregão eletrônico, específica para aquisições de bens e serviços comuns. A Figura 1 apresenta as etapas para execução indireta das obras públicas.

Figura 1 - Fluxograma das etapas para execução indireta de obras públicas

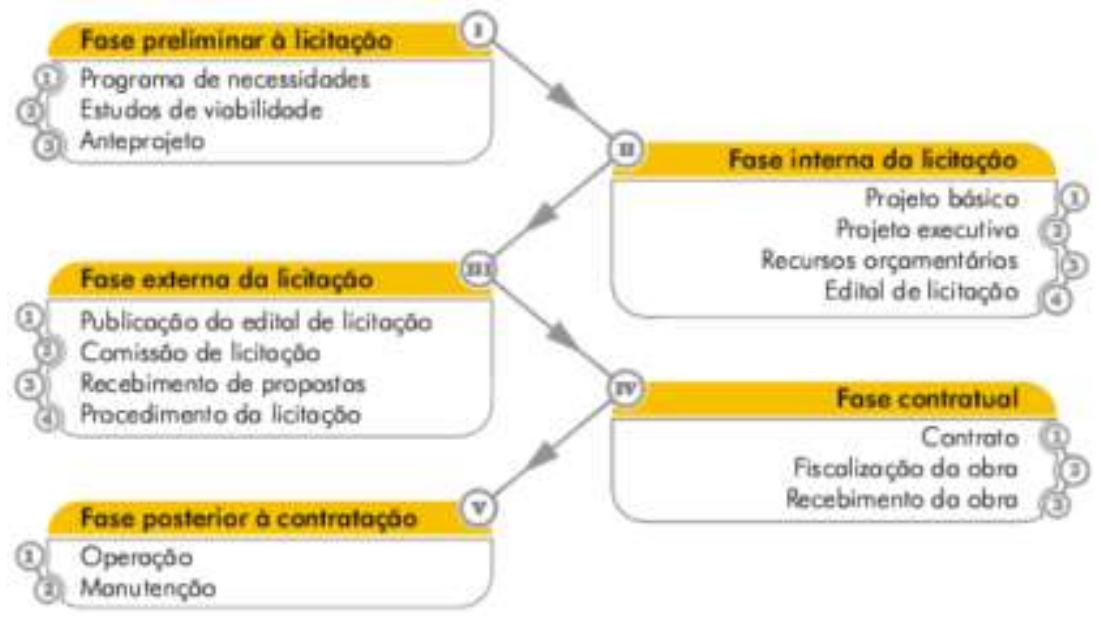

Fonte: Tribunal de Contas da União - TCU (2013, p. 12) 
As etapas previstas pelo Tribunal de Contas da União (TCU, 2013) descrevem todas as fases para que o processo licitatório ocorra de forma adequada. Borges (2008, p. 91) argumenta que "uma obra pública mal planejada está fadada ao desperdício e ao insucesso. E a escassez de recursos financeiros torna cada vez mais valiosa a técnica para aplicação de recursos". O planejamento é essencial para o sucesso de qualquer empreendimento. Cardoso (2011) defende que a falta ou falha nesta etapa é considerado o principal motivo da baixa produtividade, baixa qualidade e elevadas perdas no ramo.

A fase interna da licitação contempla os processos básicos para abertura do processo licitatório e é constituído pelas etapas de: elaboração do projeto básico, do projeto executivo, recursos orçamentários e do edital de licitação. Mânica e Lahoz (2015, p. 92) informam que no projeto básico "são estabelecidos à metodologia de execução, o cronograma, os recursos financeiros disponíveis, os materiais e serviços necessários para a execução da obra”. Matipa (2008) declara que o levantamento quantitativo dos serviços do projeto fornece o ponto de partida para a avaliação global do papel da gestão de custos do projeto.

A eficiência, a precisão e a adequação à obra são preceitos essenciais que devem estar contidos na elaboração do projeto básico. A própria Lei 8.666/93 no seu art. 6º inciso IX (Brasil, 1993), descreve didaticamente as características que o projeto deve conter. Borges (2008, p. 91) considera que "o projeto básico de uma obra pública é a peça mais importante para execução de uma obra de qualidade ao custo de mercado e que traga benefícios à população". Borges (2008) ainda aponta que o projeto básico de uma obra pública é formado pelos seguintes elementos: 1) projetos; 2) memorial descritivo com as especificações técnicas (caderno de encargos); 3) orçamento; e 4) cronograma físico-financeiro.

A Resolução ํㅜ 361/1991 do Conselho Federal de Engenharia, Arquitetura e Agronomia (CONFEA, 1991) enfatiza que o projeto básico deve conter características básicas e de desempenho dos serviços de tal modo que seja possível estimar seu custo e prazo de execução, e ainda traz no art. $3^{\circ}$, alínea "f" como forma de medir a eficiência de um projeto o percentual de precisão de mais ou menos $15 \%$, este percentual se refere aos ajustes, caso necessário, para a conclusão da obra. Já a Lei 8.666/93 (Brasil, 1993) autoriza um ajuste de até 25\%, o que contemplaria uma possível falha na previsão/ elaboração do projeto básico. 
Gusmão (2008, p. 14) diz que "a deficiência dos projetos básicos de empreendimentos públicos constitui numa das principais causas de irregularidades na execução dos contratos", todavia, essa deficiência não encontra amparo na legislação, onde o conceito de projeto básico é bem amplo como já citado anteriormente.

O projeto executivo que se trata do detalhamento máximo de cada etapa da obra apresentado no projeto básico e, portanto, ideal para o planejamento, porém, a Lei 8.666/93 (Brasil, 1993) admite que em circunstâncias específicas e com prévia autorização da administração o projeto executivo seja elaborado em concomitância com a execução da obra. No próximo tópico serão abordados alguns dos fatores determinantes para o planejamento do tempo de execução das obras e estes devem ser considerados na elaboração do projeto básico e no executivo.

\subsubsection{A variável prazo na execução das obras}

O tempo de execução das obras é uma das variáveis reconhecidas como necessária para a eficiência de um processo produtivo, além do tempo o conceito de produtividade atribuído por Souza (1996) envolve outras competências como custo, qualidade, flexibilidade e inovação.

Estas variáveis estão inter-relacionadas, uma vez que o planejamento correto do tempo evita a elevação dos custos, da mesma forma a qualidade e as inovações nos processos produtivos podem evitar retrabalho diminuir o tempo de produção e, consequentemente, diminuir os custos. Corrêa e Corrêa (2005), entretanto, explicam que um projeto pode ser visto como um conjunto único com atividades interrelacionadas, mas estudado com um determinado objetivo: específico na qualidade; específico no tempo; ou, específico no custo. Stoy e Schalcher (2007), assim como Cristóbal (2009), dizem que o sucesso do empreendimento depende da estimativa correta dos custos e que os fatores tempo, preço e qualidade desempenham um papel importante no processo.

Já Barcaui, Borba, Silva e Neves (2010) entendem que o tempo é o único recurso do projeto onde sua recuperação é impossível. Silva (2015) concorda e diz ainda que ele é o principal indicador e a falta de administração do tempo pode acarretar no desempenho global do projeto. Dada à importância da variável tempo 
que impacta na eficiência do processo faz se necessário que o planejamento desta competência seja criterioso. Figueiredo (2009) cita que existem vários softwares de gestão de projetos que auxiliam na programação dos projetos mais complexos, entre eles o Ms Project da Microsoft ${ }^{\circledR}$ e o Primavera da STEI (Serviços Técnicos de Engenharia e Informática).

Quanto aos projetos de obras da construção civil, pode-se dizer que esse setor apresenta várias particularidades em relação aos demais. Toledo, Abreu e Jungles (2000) destacam que essas atividades têm características próprias em relação ao produto e concluem que o mesmo possui natureza única e vida útil longa em relação à cadeia produtiva e caracteriza-se pela dependência entre empresas e dependência de outros setores industriais e com uma baixa frequência de inovações radicais.

Esse sistema de dependência também é citado por Miozzo e Dewick (2005), que entendem que é necessário gerenciar redes de relacionamento complexas e isso torna o processo de inovação mais lento. Além disso, Câmara e Bergamasco (2005) complementam que o setor está condicionado a intervenções de agências reguladoras que podem impor restrições e incertezas por requererem normalmente procedimentos e não desempenho.

As características mencionadas pelos referidos autores também impactam no tempo de execução e, consequentemente, nos custos da obra, a forma com que cada construtora gerencia sua rede de relacionamento reflete no tempo de execução da obra e, por sua vez, seus custos. Na atividade de construção civil são reconhecidos como custos os dispêndios: de mão de obra; com materiais; do consumo da vida útil dos equipamentos; da administração da obra; entre outros (CASTRO; ROQUE; ROSA; BONFIN, 1997; OLIVEIRA, 2011; TISAKA, 2006).

Deste modo, na determinação do tempo de execução como fatores internos críticos para a empresa pode-se citar o desempenho prático dos funcionários, a experiência no ramo, bem como o número de colaboradores, o maquinário disponível e a rede de relacionamento da empresa. Figueiredo (2009) cita além da eficiência da mão de obra atrelada aquelas em função do número de funcionários e de equipamentos disponíveis ou mesmo do tempo de experiência dos colaboradores na execução das atividades e o aspecto externo que diz respeito às condições 
climáticas, atraso de entrega de materiais por conta do fornecedor e peculiaridades de cada região.

$\mathrm{Na}$ administração pública o prazo de execução das obras é calculado em função das atividades, da expertise dos engenheiros e da expectativa da administração, desta forma, cabe à empreiteira avaliar se pode ou não realizar no tempo estipulado e calcular sua proposta de custo global com esta variável. Contudo, no que cabe a administração pública, Gomes (2007) afirma que os atrasos ocorrem por projetos mal formulados ou incompletos e ainda pelo atraso no pagamento das tarefas executadas.

A base para o planejamento é um projeto bem definido e completo. Vários autores entendem que a qualidade nas obras públicas somente será atingida com melhores projetos e com gestão eficiente dos mesmos (BRETAS, 2010; CANONICO, 2011; GOMES, 2007; SILVA, 2011; MAYR; VARVAKIS, 2005).

\subsubsection{Estudos e pesquisas sobre o tema}

Na pesquisa realizada por Alnuaimi, Taha, Mohsin e Harthi (2010), os dados encontrados revelam que em Omã no Oriente Médio, os trabalhos adicionais do cliente e as modificações no projeto foram os fatores mais importantes causadores dos atrasos dos cronogramas seguidos pela não disponibilidade de manuais e procedimentos de construção.

Já na Arábia Saudita, Assaf e Al-Hejji (2006) realizaram um estudo de campo com 23 empreiteiros, 19 consultores e 15 proprietários - setenta e três causas de atraso foram identificadas durante a pesquisa - onde $76 \%$ dos contratados e $56 \%$ dos consultores indicaram que a média de tempo excedido está entre 10\% e 30\% da duração original. A causa mais comum de atraso identificada por todas as três partes é "ordem de mudança“. Os pesquisadores evidenciam que $70 \%$ dos projetos registraram um excesso de tempo na execução dos empreendimentos.

Enquanto que na Dinamarca, o trabalho de Larsen, Shen, Lindhard e Brunoe (2016) apontou que o fator mais influente para a variável tempo é a incerteza ou falta de financiamento do projeto. A principal conclusão desta pesquisa é que o cronograma do projeto, orçamento e nível de qualidade são afetados de maneiras significativamente diferentes. Santos, Starling e Andery (2014) apresentam em seu 
trabalho problemas no cronograma das obras públicas de países como: Índia; Jordânia; e Nigéria.

$\mathrm{Na}$ busca por pesquisas acerca do assunto no Brasil, de forma mais específica, encontrou-se o trabalho de Coutinho (2010) que estudou os prazos das obras licitadas e concluídas na Universidade Federal do Pará UFPA - no período de 2006 a 2009. As obras apresentaram atrasos considerados pela autora de grande intensidade, o percentual descrito é de $32,57 \%, 50,67 \%, 103,27 \%$ e $52,74 \%$, a mesma pesquisa traz dados da Fundação de Amparo e Desenvolvimento da Pesquisa - FADESP onde para o mesmo período os percentuais são de $61,63 \%$, $46,34 \%, 80,28 \%$ e $97,30 \%$.

Ainda no campo da administração pública localizou-se o trabalho de Santos et al. (2014) que em seu estudo de caso em uma autarquia municipal aponta que no conjunto de 126 obras no período de 2009 a 2013, 96\% dos contratos tiveram aditivo de prazo e que o tempo em média foi acrescido de $111 \%$ do previsto incialmente.

\subsection{Procedimentos Metodológicos}

\subsubsection{Caracterização Metodológica}

Vergara (2016) propõe dois critérios básicos para classificar a pesquisa: quanto aos fins e quanto aos meios. Dessa forma, quanto aos fins classifica-se como descritivo e, quanto aos meios, é classificada como documental. Nesse sentido, a pesquisa documental é definida por Gil (2010) como a que utiliza vários documentos, elaborados para diversas finalidades, sendo estes materiais internos da organização, diferentemente da pesquisa bibliográfica que trata de documentos geralmente encontrados em bibliotecas ou banco de dados.

Além disso, Godoy (1995) argumenta que a pesquisa documental é apropriada nos estudos de longos períodos de tempo, onde se busca identificar as tendências do comportamento de um determinado fenômeno e ressalta três aspectos importantes neste tipo de pesquisa: a escolha dos documentos, o acesso a eles e a sua análise. Sendo assim, no que se refere à escolha, se tem no presente trabalho a pasta de contratos, onde constam todos os documentos, desde os que antecedem ou justificam o início da licitação até o documento final de entrega da 
obra. O acesso é público - em virtude de ser um documento público - e acerca da análise optou-se por descrever os achados, e assim, identificar o lapso de tempo entre a contratação e a execução das obras, comparando o tempo programado e presente no contrato entre órgão público e executor e o tempo final dispendido para a execução da obra.

De forma empírica, por meio de observação dos pesquisadores e através da divulgação na mídia os atrasos nas obras da instituição são publicitados, porém, a intenção é verificar qual a média dos atrasos e, com descarte as especulações, quais justificativas formais têm sido utilizadas. Deste modo, considerando que não cabem as percepções dos envolvidos, mas sim, a busca documental das referidas motivações que levaram a administração pública a concordar com o aditivo, em função disso, se deve aqui a escolha das fontes de evidência com base na pesquisa documental para a realização do presente estudo.

A escolha da pesquisa descritiva vem ao encontro da estratégia citada por Michel (2015), em virtude do propósito da mesma, ou seja, que é analisar com maior precisão, tanto fatos como fenômenos em sua natureza e características, sendo possível observar suas relações, conexões e interferências, e também, de poder ser visto como um problema contemporâneo da vida real.

Ademais, caracteriza-se o estudo como descritivo dado que o trabalho revela as características dos contratos analisados e se tem a pretensão de quantificar em dias os atrasos médios da execução das obras públicas e identificar as justificativas dos referidos aditivos ao contrato. Quanto ao período escolhido, pode ser dito como um período aquecido pelos recursos advindos das Políticas Públicas de Expansão e Reestruturação das Universidades Federais REUNI.

\subsubsection{Coleta de Dados}

A partir da abordagem mencionada foi realizada a coleta de dados que teve início no mês de setembro de 2015 e se estendeu até o mês de fevereiro de 2016 e pode ser descrita através de três etapas distintas. A primeira etapa foi realizada no setor de Contratos e Convênios na busca dos contratos de serviços de engenharia pactuados entre empresas e a instituição pública. 
Assim, foram selecionados 85 contratos dentro do período pretendido que apresentaram como objeto obras, construções e ampliações, já excluídos os contratos de reformas, de pavimentação de ruas e obras pertencentes ao hospital universitário, devido a especificidades destes.

A segunda etapa se deu na busca das pastas de cada contrato, onde foram encontrados 56 obras, os demais contratos estavam em trâmite por outros setores ou já arquivados. Na coleta de dados selecionou-se para cada obra o prazo em dias planejado para a conclusão da obra, este prazo consta no contrato assinado e acordado entre as partes. Após, verificou-se as solicitações e justificativas de aditamento de prazo para conclusão das obras e o aceite das mesmas por meio da formalização de aditivos aos contratos. Estes prazos adicionais foram somados ao prazo inicial e, desta forma, se estabeleceu o tempo da execução dos serviços.

No tocante da motivação para concessão de novo prazo de conclusão, foram citadas mais de uma justificativa, assim quando isso ocorreu sem a citação do tempo para cada motivação, os dias totais da solicitação foram divididos de forma igual para as justificativas apresentadas.

No tratamento dos dados foram percebidas diferenças estruturais entre as obras que poderiam distorcer os resultados, deste modo, observando as descrições do objeto específico dos contratos, optou-se pela segregação em grandes grupos, pois se acredita que desta forma os resultados podem descrever de melhor forma a realidade.

\subsection{Apresentação e Análise dos resultados}

\subsubsection{Apresentação dos tempos planejados e de execução das obras}

O planejamento do tempo de execução de uma obra pública é realizado tendo como base o projeto básico ou, quando possível, o projeto executivo da mesma, embora este último muitas vezes só esteja pronto após o procedimento licitatório instaurado. Este fato é um agravante, pois o planejamento depende de uma base sólida e o projeto básico nem sempre apresenta todo o detalhamento da obra, embora, conforme aponta o referencial teórico aqui abordado o mesmo deva apresentar todas as condições para o planejamento de execução. 
Mas o projeto básico não pode ser considerado a única variável para a desigualdade entre os tempos. Das 56 obras selecionadas, 11 delas tiveram o contrato rescindido, e a rescisão se deu de forma unilateral e imposta pela administração pública, ademais, em todos os casos a motivação foi: o atraso no início das obras ou o atraso no cronograma físico e a gestão identificou falta de justificativa ou ainda justificativa incoerente.

Já o Gráfico 1 apresenta os resultados encontrados nas demais obras, no total de 45 obras. Na base horizontal do gráfico é indicado o número do contrato e o ano de início do processo de forma sintetizada, já na base vertical é apresentado o tempo em dias.

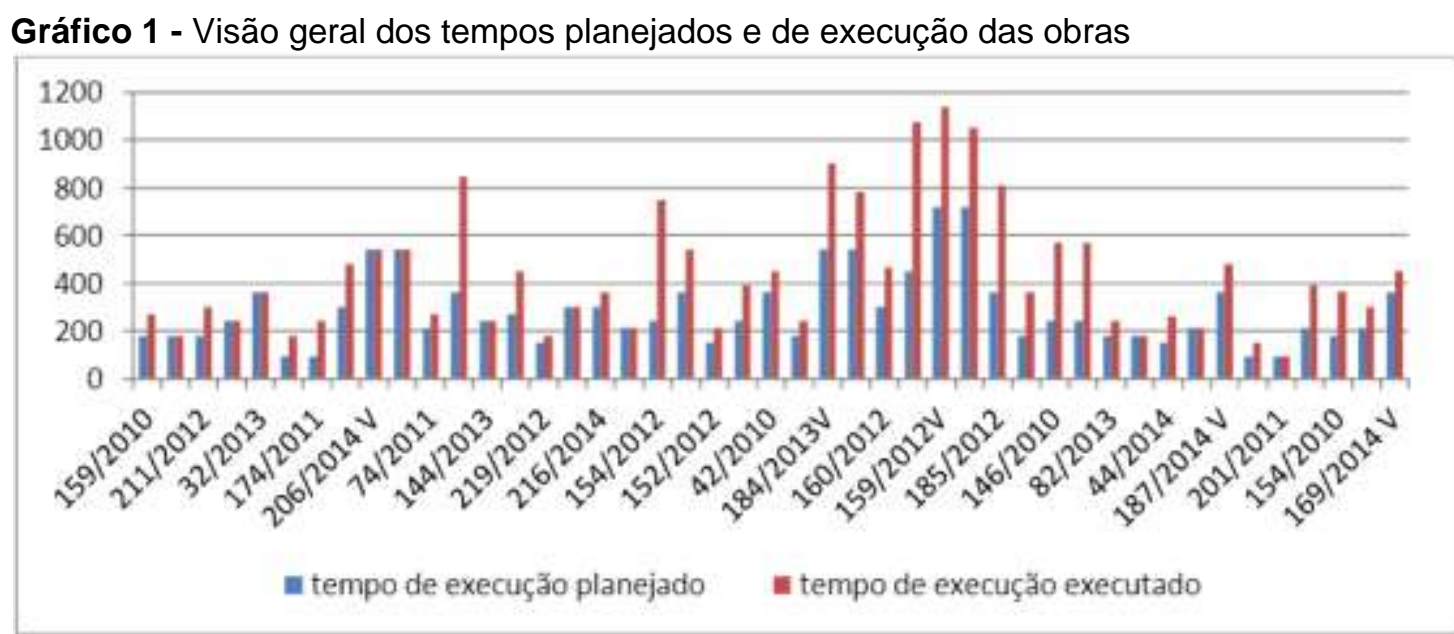

Fonte: Autores

O Gráfico 1 apresenta 45 obras destas apenas 11 obras não tiveram termo aditivo de tempo, desta forma, $75,55 \%$ do total das obras estudadas apresentaram aumento no prazo para conclusão do projeto. Já considerado o grupo dos contratos rescindidos em função do atraso no cronograma sem justificativa ou com justificativa indeferida pela administração pública este percentual é de 80,35\%.

No conjunto dos contratos sem rescisão e com aditivo de tempo, a média de erro estimado para a amostra dos quarenta e cinco contratos é 144,20 dias, percentual de $48,94 \%$. O tempo total planejado para todas as obras foi de 13.260 dias e o tempo total de conclusão dessas obras foi de 19.749 dias. 


\subsubsection{Análise do tempo por grupos}

Visto que as obras apresentam características diferenciadas, as mesmas foram segregadas em grupos de acordo com a descrição da obra apresentada na planilha de controle dos contratos. Os grupos formados foram: grupo ampliação; grupo construção; grupo prédios; e o grupo dos pré-moldados.

a) Grupo Ampliação: indicação quando o objeto da contratação se trata de serviço de engenharia contratado para ampliar ou complementar uma construção já existente. Forma de construção convencional;

b) Grupo Construção: indicado quando o objeto da contratação se trata de um serviço de engenharia para a construção inicial de um espaço físico no formato horizontal. Forma de construção convencional;

c) Grupo Prédios: indicado quando o objeto da contratação se trata de um serviço de engenharia para a construção inicial de um espaço físico no formato vertical, sendo dividido em andares de utilização pública. Forma de construção convencional; e

d) Grupo Pré-moldado: indicado quando o objeto da contratação se trata de um serviço de engenharia para a construção inicial de um espaço físico, cuja forma de construção seja pré-fabricada. Parte da construção é realizada em outro ambiente, sendo transportada já pronta para a montagem no local físico final.

Sendo assim, na Tabela 1 observa-se o número de obras que contempla cada grupo e as médias do tempo de planejamento em dias para a execução dos serviços, assim como o tempo médio utilizado até o término da referida obra, na última coluna é apresentada a diferença da média em dias dos atrasos, que não sofre diferença em relação ao número de aditivos e o total de obras do grupo. 
Tabela 1 - Tempo Médio de Planejamento versus Tempo Médio de Execução em dias das Obras

\begin{tabular}{lcccccc}
\hline Grupo & $\begin{array}{c}\text { Número } \\
\text { de } \\
\text { obras }\end{array}$ & $\begin{array}{c}\text { Obras } \\
\text { com } \\
\text { aditivos }\end{array}$ & $\begin{array}{c}\text { Tempo Médio } \\
\text { Planejamento }\end{array}$ & $\begin{array}{c}\text { Tempo } \\
\text { Médio de } \\
\text { Execução }\end{array}$ & $\begin{array}{c}\text { Diferença da } \\
\text { Média de } \\
\text { Dias }\end{array}$ & $\begin{array}{c}\% \\
\text { Atraso }\end{array}$ \\
\hline Ampliação & 10 & 5 & 270 & 333 & 63 & $23,33 \%$ \\
Construção & 15 & 12 & 274 & 422 & 148 & $54,09 \%$ \\
Prédios & 09 & 8 & 417 & 758 & 341 & $81,83 \%$ \\
Pré-Moldados & 11 & 7 & 180 & 260 & 90 & $40,32 \%$ \\
\hline
\end{tabular}

Fonte: Autores

Pela análise na Tabela 1 verifica-se que no grupo Ampliação a média de erro entre o planejamento e a execução foi de 63 dias de atraso e o percentual de 23,33\%. Neste grupo 5 obras tiveram aditivo de tempo. O grupo construção é composto por 15 unidades e indica uma média de 148,33 dias, o que representa um percentual de $54,09 \%$ de atraso no tempo planejado para a conclusão das obras, sendo que 12 obras tiveram aditivo de tempo.

O grupo prédios é formado por 9 construções e a média de erro no planejamento é de 341 dias, representando um percentual de atraso de 81,83\%. Neste grupo 8 obras tiveram aditivo de tempo. A construção com base em prémoldados soma 11 obras e indica um erro de planejamento do tempo de aproximadamente 81 dias, com um percentual de atraso de 40,32\%, onde 7 obras tiveram aditivo de tempo.

Dentre os grupos estudados, o grupo ampliação é o que apresenta um menor erro do tempo de planejamento, como também, o menor índice de aditivos aos contratos, e o grupo de prédios é o que exibe um maior erro no tempo de planejamento e o maior número de aditivos em relação ao total de obras. No próximo tópico são apresentadas as causas citadas como justificativas para o aumento no prazo de execução das obras.

\subsubsection{Causas dos termos aditivos de tempo}

O tempo de execução das obras apresenta-se superior ao tempo planejado em praticamente todas as obras analisadas, em função disso, considera-se 
importante detectar as causas destes aditivos de tempo. A Tabela 2 revela as principais causas dos aditivos de tempo.

Tabela 2 - Principais Causas dos Aditivos de Tempo

\begin{tabular}{lccccccc}
\hline Causas/dias em atrasos & 2010 & 2011 & 2012 & 2013 & 2014 & Soma & Méd Pond. \\
\hline Alteração local obra & 90 & 0 & 0 & 365 & 0 & 455 & 5,25 \\
Alteração projeto/ ajustes & 845 & 135 & 975 & 575 & 360 & 2890 & 33,38 \\
Inclusão projeto & 390 & 0 & 210 & 0 & 0 & 600 & 6,93 \\
Clima - chuvas & 135 & 0 & 630 & 335 & 80 & 1180 & 13,63 \\
Escassez Mão de Obra & 860 & 135 & 210 & 65 & 0 & 1270 & 14,67 \\
Atraso entrega matéria- & 50 & 0 & 255 & 45 & 30 & 380 & 4,39 \\
prima & 0 & 0 & 0 & 240 & 90 & 330 & 3,81 \\
Greve dos servidores & 1150 & 180 & 224 & 0 & 0 & 1554 & 17,94 \\
*Inviabilidade do terreno & & & & & & & \\
\hline
\end{tabular}

*terreno não liberado pela instituição ou na dependência de outra obra

Fonte: Autores

Os aditivos estão agrupados pela data de emissão dos contratos, desta forma, um contrato de 2010 pode ter sofrido um aditivo de uma causa específica, ocorrida nos períodos seguintes, anos de 2011 ou 2012. Cabe frisar que os valores nas colunas dos anos representam os dias somados dos aditivos de prazo dos referidos contratos

Assim, considerado os dias aditivados aos contratos tem-se como primeira causa a alteração de projetos, ajustes de projetos e aparece de forma significativa em todos os períodos dos contratos. A segunda causa em índice é a inviabilidade de acesso ao terreno ou aguardando o término ou ajuste de outra obra, com 17,94\%, o fato positivo neste percentual é que a composição do mesmo se deu nos exercícios de 2010 a 2012 não aparecendo nos exercícios de 2013 e 2014.

A escassez de mão de obra aparece em terceira posição, $14,67 \%$, e é incluída nos contratos de 2010 a 2012 com ênfase e retraída em 2013 e 2014. Este fato apesar de negativo para a instituição reflete o aquecimento da construção civil no período de 2011 e 2012. Neste período na cidade sede da instituição foram realizadas várias obras, motivadas pela facilitação ao crédito para construção residencial pelo Programa Minha Casa Minha Vida; e as moradias destinados à população de baixa renda do Programa Arrendamento Residencial - PAR. 
O clima e as chuvas aparecem em quarto lugar, com $13,63 \%$ das justificativas para aditamento do tempo de execução da obra. Os índices que aparecem em menor proporção são os derivados da greve dos servidores - com 3,81\% - e o atraso da entrega da matéria-prima - com 4,39\%. O índice referente à inclusão de projeto apresenta percentual de 6,93\%, ocorrendo em apenas dois períodos, esse item é pontuado apenas quando um projeto é incluso, ou seja, não havia previsão inicial do projeto. Quanto realizados ajustes, complementos ou alterações esses são registrados como causa própria.

Coutinho (2010) buscou desenvolver um modelo numérico prognóstico para tratar a variável tempo nas obras de engenharia civil na UFPA no período de 2006 a 2009 e concluiu que $79,60 \%$ da variabilidade do tempo de execução das obras são causadas ou produzidas em conjunto pelos seguintes elementos: área, orçamento, capacidade técnica operacional das Instituições Federais de Ensino Superior, capacidade operacional da empresa, do tipo de serviço e da estação do ano. Neste trabalho, desconsiderando a escassez de mão de obra e atraso matéria-prima como problemas de capacidade operacional, as outras causas somam-se $77,13 \%$ do total dos aditivos de tempo.

\section{CONSIDERAÇÕES FINAIS}

O presente estudo teve como objetivo analisar os contratos de obras de uma Universidade Federal, do período de 2010 a 2014, a fim de identificar o tempo médio dos atrasos nas obras e a justificativa escrita dos aditivos de prazo para a execução dos serviços pactuados entre as construtoras e a administração pública.

Deste modo, constatou-se que os aditivos de tempo no período analisado estão presentes em $80,34 \%$ dos contratos, desconsiderando as rescisões tem-se $75,55 \%$ das obras com um atraso médio de 144,20 dias, o que representa em percentual $48,94 \%$ de atraso entre o previsto e o real. Estes dados ficam abaixo dos estudos encontrados, apesar de serem de períodos diferentes, aplicando a média nos dados apresentados por Coutinho (2010) no trabalho desenvolvido nas obras de 2006 a 2009 tem-se um percentual de atraso de 59,81\% para a UFPA e $71,38 \%$ para a FADESP. Já o trabalho de Santos et al. (2014), em uma autarquia municipal 
no período de 2009 a 2013, 96\% tiveram aditivo de prazo e que o tempo em média foi acrescido de $111 \%$ do previsto incialmente.

No âmbito internacional o atraso é menor, o estudo de Assaf e Al-Hejji (2006) identifica que $70 \%$ dos projetos registraram um excesso de tempo. Nas justificativas dos aditivos de tempo tem-se a alteração de projetos em primeiro lugar, com percentual de 33,34\%, o que vai ao encontro do trabalho de Assaf e Al-Hejji (2006) em obras na Arábia Saudita, também aparece como fator determinante na pesquisa de Alnuaimi et al. (2010) em Omã.

$\mathrm{Na}$ comparação interna da instituição, quando segregado as obras por grupos, o grupo dos prédios é o que mais se distancia em relação as previsões iniciais, com média de $81,83 \%$ de acréscimo do tempo, já as obras de ampliação apresentam um percentual médio de $23,33 \%$ de acréscimo de tempo.

Em termos práticos, no estudo apresentado e nas pesquisas relatadas, 0 princípio da administração pública - que versa sobre a eficiência - não vem sendo alcançado na sua totalidade. Apesar de não ser possível a generalização da investigação realizada em virtude da metodologia aqui adotada, a mesma contribui para endossar a falta de eficiência no planejamento de forma global na instituição estudada, no que diz respeito ao tempo de planejamento e execução das obras no período estudado. Contudo, o trabalho demonstra que houve obras onde o prazo planejado foi concretizado.

O fato da principal justificativa para a solicitação dos aditivos ser a alteração ou ajuste dos projetos (33,34\%) reforça a ideia que a fase interna da licitação, onde o projeto básico é estruturado mereça uma maior atenção, em especial ao grupo dos prédios, o que pode resultar no alcance da eficiência estabelecida como principio da administração pública.

Ao findar esta pesquisa, como sugestões de estudos futuros - para fins comparativos - pode ser realizado um novo trabalho em obras levando em conta o mesmo período considerado por Coutinho, identificando os percentuais por ano. Além disso, com o propósito de ampliar a análise efetuada, podem ser verificadas outras instituições de ensino superior, bem como outros órgãos públicos admitindo a relevância do tema para a sociedade, a fim de acompanhar o andamento das obras e cobrar, se for o caso, a melhor destinação recursos, objetivando assim, o término da obra. 


\section{REFERÊNCIAS}

ALNUAIMI, A. S.; TAHA, R. A.; MOHSIN, M. Al; HARTHI, Ali Al - S. Causes, effects, benefits, and remedies of change orders on public construction projects in Oman. Journal of Construction Engineering and Management, v. 136, n. 5, p. 615-618, May 2010. DOI: https://doi.org/10.1061/(ASCE)CO.1943-7862.0000154

ANTUNES, P. A. L. D. Desvios de prazos e de custos na execução de empreitadas de obras públicas. 2012. 123 f. Dissertação (Mestrado em Engenharia Civil) - Departamento de Engenharia Civil - Universidade Lusófona de Humanidades e Tecnologias, Lisboa, 2012.

ASSAF, S. A.; AL-HEJJI, S. Causes of delay in large construction projects. International Journal of Project Management, v. 24, n. 4, p. 349-357, May 2006. DOI: https://doi.org/10.1016/j.ijproman.2005.11.010

BARCAUI, A. B.; BORBA, DA SILVA, I. M.; NEVES, R. B. Gerenciamento do tempo em projetos. 3. ed. Rio de Janeiro: FGV, 2010.

BARRETO, S. L.; SOUTO, M. J. V. Licitação: conceito, princípios, direito comparado e regulação. Rio de Janeiro: FGV, 2008.

BITTENCOURT, M. F. N.; FERREIRA, P. A. As obras na implementação de políticas públicas: o caso do REUNI. In: ENCONTRO DA ANPAD, 38., Rio de Janeiro, 2014. Anais... Rio de Janeiro: EnANPAD, 2014.

BORGES, C. L. C. Procedimentos para elaboração do projeto básico para obras públicas. Revista Engenharia, São Paulo, v. 588, n. 1, p. 90-95, 2008.

BRASIL. Constituição da República Federativa do Brasil de 1988. Recuperado de http://www.planalto.gov.br/ccivil 03/constituição/constituição.htm

BRASIL. Lei n. 10.520, de 17 de julho de 2002. Recuperado de http://www.planalto.gov.br/ccivil 03/leis/2002/L10520.htm

BRASIL. Lei n. 12.349, de 15 de dezembro de 2010. Recuperado de http://www.planalto.gov.br/ccivil 03/ Ato2007-2010/2010/Lei/L12349.htm

BRASIL. Lei n. 8.666, de 21 de junho de 1993. Regulamenta o art. 37, inciso XXI, da Constituição Federal, institui normas para licitações e contratos da Administração Pública e dá outras providências. Recuperado de http://www.planalto.gov.br/ccivil 03/leis/L8666cons.htm

BRETAS, E. S. O processo de projetos de edificações em instituições públicas: proposta de um modelo simplificado de coordenação. 2010. 151 f. Dissertação (Mestrado em Construção Civil) - Programa de Pós-Graduação em Construção Civil - Universidade Federal de Minas Gerais, Belo Horizonte, 2010.

CÂMARA, M. R. G.; BERGAMASCO, F. L. Competitividade e inovação nas empresas de construção civil de Londrina. In: SEMINÁRIO LATINO-IBERO AMERICANO DE GESTIÓN TECNOLÓGICA, Salvador, 2005. Anais... Salvador: ALTEC, 2005.

CANONICO, M. R. S. O. Proposta de processo para a elaboração da fase interna da licitação na contratação de obras de construção civil pelo setor público. 2011. $147 \mathrm{f}$. 
Dissertação (Mestrado em Engenharia Civil) - Programa de Pós-Graduação em Engenharia Civil - Universidade Tecnológica Federal do Paraná, Curitiba, 2011.

CARDOSO, R. S. Orçamento de obras em foco: um novo olhar sobre a engenharia de custos. 2. ed. São Paulo: Pini, 2011.

CARVALHO FILHO, J. dos S. Manual de direito administrativo. 26. ed. São Paulo: Atlas, 2013

CASTRO, J. E. E.; ROQUE, R. F.; ROSA, G. S.; BONFIN, N. S. Custos administrativos na construção civil - estudo de caso. In: ENCONTRO NACIONAL DE ENGENHARIA DE PRODUÇÃO, 17., Gramado, 1997. Anais... Gramado: ENEGEP, 1997.

CONFEA. Resolução no 361/91, de 10 de dezembro de 1991. Dispõe sobre a conceituação de Projeto Básico em Consultoria de Engenharia, Arquitetura e Agronomia. Diário Oficial da União: República Federativa do Brasil, Brasília, 12 dez. 1991.

CORRÊA, C. A.; CORRÊA, H. L. Administração de produção e de operações: manufatura e serviços: uma abordagem estratégica. 2. ed. São Paulo: Atlas, 2005.

COUTINHO, L. S. de A. L. Modelagem do "tempo de execução" de obras civis: estudo de caso na Universidade Federal do Pará - UFPA. 2010. 196 f. Dissertação (Mestrado em Engenharia Civil) - Programa de Pós-Graduação em Engenharia Civil - Universidade Federal do Pará, Belém, 2010.

CRISTÓBAL, J. R. S. Time, cost and quality in a road building project. Journal of construction engineering and management, v. 135, n. 11, p. 1271-1274. November 2009. DOI: https://doi.org/10.1061/(ASCE)CO.1943-7862.0000094

DI PIETRO, M. S. Z. Direito administrativo. 26. ed. São Paulo: Atlas, 2013.

DRUCKER, P. F. The effective executive. New York: Harper and Row, 1967.

FIGUEIREDO, L. Planejamento e programação de um projeto de construção civil. 2009. 135 f. Monografia (Graduação em Engenharia de Produção) - Escola Politécnica Universidade de São Paulo, São Paulo, 2009.

GIL, A. C. Como elaborar projetos de pesquisa. 5. ed. São Paulo: Atlas, 2010.

GODOY, A. S. Pesquisa qualitativa: tipos fundamentais. Revista de Administração de Empresas, São Paulo, v. 35, n. 3, p. 20-29, maio/jun. 1995. DOI: https://doi.org/10.1590/S0034-75901995000300004

GOMES, R. C. G. A postura das empresas construtoras de obras públicas da grande Florianópolis em relação ao PBQP-H. 2007. 173 f. Dissertação (Mestrado em Engenharia Civil) - Programa de Pós-Graduação em Engenharia Civil - Universidade Federal de Santa Catarina, Florianópolis, 2007.

GUSMÃO, J. R. L. Planejamento na contratação de obras públicas: estudo das disposições legais sobre projeto básico, licenciamento ambiental, definição dos custos e fonte dos recursos no processo de contratação de empreendimentos públicos. 2008. $70 \mathrm{f}$. Monografia (Especialista em Gerenciamento de Obras) - Escola Politécnica - Universidade Federal da Bahia, Salvador, 2008. 
JUSTEN FILHO, M. Curso de direito administrativo. 10. ed. São Paulo: RT, 2014.

LARSEN, J. K.; SHEN, G. Q.; LINDHARD, S. M.; BRUNOE, T. D. Factors affecting schedule delay, cost overrun, and quality level in public construction projects. Journal of

Management in Engineering, v. 32, n. 1, p. 1-10, January 2016. DOI:

https://doi.org/10.1061/(ASCE)ME.1943-5479.0000391

MÂNICA, F. B.; LAHOZ, R. A. L. Contratos de obra: critérios de medição, pagamento e inconsistência no projeto básico. Revista de Contratos Públicos, v. 3, n. 5, p. 85-97, Fevereiro 2015.

MATIPA, W. M. Total cost management at the design stage using a building product mode. 2008. (Thesis of Doctorate) - Department of Civil and Environmental Engineering National University of Ireland, Cork, 2008.

MAYR, L. R.; VARVAKIS, G. Ruídos no processo de comunicação: o caso de obras públicas realizadas para a UFSC. In: SEMINÁRIO DE TECNOLOGIA DA INFORMAÇÃO E COMUNICAÇÃO NA CONSTRUÇÃO CIVIL, 2., São Paulo, 2005. Anais... São Paulo, 2005

MEIRELLES, H. L. Direito administrativo brasileiro. 23. ed. São Paulo: Malheiros Editores, 1998.

MELLO, C. A. B. de. Curso de direito administrativo. 30. ed. São Paulo: Malheiros, 2013.

MICHEL, M. H. Metodologia e pesquisa científica em ciências sociais: um guia prático para acompanhamento da disciplina e elaboração de trabalhos monográficos. 3. ed. São Paulo: Atlas, 2015.

MIOZZO, M.; DEWICK, P. Building competitive advantage: innovation and corporate governance in European construction. Research Policy: Elselvier, 2005.

ODEH, A. M.; BATTAINEH, H. T. Causes of construction delay: traditional contracts. International Journal of Project Management, v. 20, n. 1, p. 67-73, January 2002. DOI: https://doi.org/10.1016/S0263-7863(00)00037-5

OLIVEIRA, A. F. DE; GUELBERT, T. F.; GUELBERT, M. G. Análise das causas de atrasos em empreendimentos residenciais relacionadas às falhas na gestão de projetos. In: CONGRESSO BRASILEIRO DE ENGENHARIA DE PRODUÇÃO, 6., Ponta Grossa, 2010. Anais... Ponta Grossa: CONBREPRO, 2016.

OLIVEIRA, J. S. de. Custos na construção civil brasileira. 2011. 70 f. Monografia (Graduação em Ciências Econômicas) - Departamento de Ciências Econômicas Universidade Federal de Santa Catarina, Florianópolis, 2011.

RASMUSSEN, A. F. M. Gestão de obras públicas: um diagnóstico sobre aditivos de contratos. 2013. 108 f. Dissertação (Mestrado em Arquitetura e Urbanismo) - Instituto de Arquitetura e Urbanismo - Universidade de São Paulo, São Carlos, 2013.

SANTOS, H. de P.; STARLING, C. M. D.; ANDERY, P. R. P. Diagnóstico e análise de aditivos contratuais em obras públicas de edificações. In: ENCONTRO NACIONAL DE TECNOLOGIA DO AMBIENTE CONSTRUÍDO, 15., Maceió, 2014. Anais... Maceió, 2014.DOI: https://doi.org/10.17012/entac2014.193 
SANTOS, H. de P.; STARLING, C. M. D.; ANDERY, P. R. P. Um estudo sobre as causas de aumentos de custos e de prazos em obras de edificações públicas municipais. Ambiente Construído, Porto Alegre, v. 15, n. 4, p. 225-242, out./dez. 2015.DOI:

https://doi.org/10.1590/s1678-86212015000400048

SILVA, C. F. Análise de falhas em projetos de construção civil. 2015 (artigo) Instituto de Educação Tecnológica - Pós-graduação de Gestão de Projetos em Construção e Montagem. Recuperado de http://www.ietec.com.br/clipping/2015/boletim/agosto/gp-agosto-analisefalhas-projetos-construcao-civil.pdf

SILVA, M. E. M. da. Diretrizes para a gestão de projetos de obras públicas: o caso da UFPA. 2011. 123 f. Dissertação (Mestrado em Engenharia Civil) - Programa de PósGraduação em Engenharia Civil - Universidade Federal do Pará, Belém, 2011.

SOUZA, U. E. L. de. Metodologia para o estudo da produtividade da mão-de-obra no serviço de fôrmas para estruturas de concreto armado. 1996. 280 f. Tese (Doutorado em Engenharia Civil) - Escola Politécnica - Universidade de São Paulo, São Paulo, 1996.

STOY, C.; SCHALCHER, H. Residential building projects: building cost indicators and drivers. Journal of Construction Engineering and Management, v. 133, n. 2, p. 139-145, February 2007. DOI: https://doi.org/10.1061/(ASCE)0733-9364(2007)133:2(139)

STRAPASSON, D. C.; SANTOS, A. dos; SANTOS, A. de P. L. Falhas de desempenho devido ao planejamento ineficaz em edificações de ensino públicas. In: ENCONTRO DE ENGENHARIA E TECNOLOGIA DOS CAMPOS GERAIS, 5., Ponta Grossa, 2010. Anais... Ponta Grossa: EETCG, 2010.

TISAKA, M. Orçamento na construção civil - consultoria, projeto e execução. 3. ed. São Paulo: Editora Pini, 2006.

TOLEDO, R. de; ABREU, A. F. de; JUNGLES, A. E. A difusão de inovações tecnológicas na indústria da construção civil. In: ENCONTRO NACIONAL DE TECNOLOGIA, DO AMBIENTE CONSTRUIDO, 2000, Salvador. Anais... Salvador: ENTAC, 2000.

TRIBUNAL DE CONTAS DA UNIÃO - TCU. Obras públicas: recomendações básicas para a contratação e fiscalização de obras de edificações públicas. 3. ed. Brasília: TCU, 2013.

VERGARA, S. C. Projetos e relatórios de pesquisa em administração. 16. ed. São Paulo: Atlas, 2016.

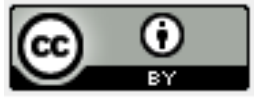

Artigo recebido em: 20/07/2018 e aceito para publicação em: 06/11/2018 DOI: http://dx.doi.org/10.14488/1676-1901.v18i4.2941 